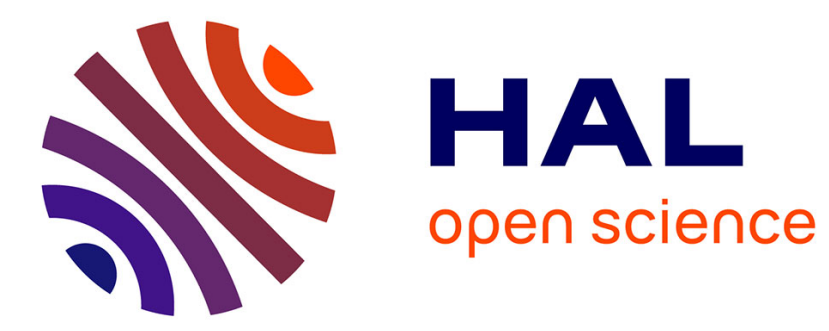

\title{
Turbulent flows in straight compound open-channel with a transverse embankment on the floodplain
}

Y. Peltier, Sébastien Proust, N. Rivière, André Paquier, K. Shiono

\section{To cite this version:}

Y. Peltier, Sébastien Proust, N. Rivière, André Paquier, K. Shiono. Turbulent flows in straight compound open-channel with a transverse embankment on the floodplain. Journal of Hydraulic Research, 2013, 51 (4), p. 446 - p. 458. 10.1080/00221686.2013.796499 . hal-01073136

\section{HAL Id: hal-01073136 https://hal.science/hal-01073136}

Submitted on 9 Oct 2014

HAL is a multi-disciplinary open access archive for the deposit and dissemination of scientific research documents, whether they are published or not. The documents may come from teaching and research institutions in France or abroad, or from public or private research centers.
L'archive ouverte pluridisciplinaire HAL, est destinée au dépôt et à la diffusion de documents scientifiques de niveau recherche, publiés ou non, émanant des établissements d'enseignement et de recherche français ou étrangers, des laboratoires publics ou privés. 
1 Turbulent flows in straight compound open-channel with a transverse

2 embankment on the floodplain

3 YANN PELTIER (IAHR Member), Ph. D., Laboratoire de Mécanique des Fluides et

4 Acoustique (LMFA, CNRS UMR5509, Université de Lyon), INSA de Lyon, Bât. Jacquard,

520 av. A. Einstein, 69621, Villeurbanne, France. Previously, Irstea, UR HHLY, Hydrology-

6 Hydraulics, 5 rue de la Doua, CS 70077, 69626 VILLEURBANNE Cedex, France.

$7 \quad$ Email: yann.peltier90@gmail.com (Corresponding Author)

8 SEBASTIEN PROUST (IAHR Member), Researcher, Irstea, UR HHLY, Hydrology-

9 Hydraulics, 5 rue de la Doua, CS 70077, 69626 VILLEURBANNE Cedex, France.

10 Email: sebastien.proust@irstea.fr

11 NICOLAS RIVIERE (IAHR Member), Professor, Laboratoire de Mécanique des Fluides et 12 Acoustique (LMFA, CNRS UMR5509, Université de Lyon), INSA de Lyon, Bât. Jacquard, 1320 av. A. Einstein, 69621, Villeurbanne, France.

14 Email: nicolas.riviere@insa-lyon.fr

15 ANDRE PAQUIER (IAHR Member), Senior Researcher, Irstea, UR HHLY, Hydrology16 Hydraulics, 5 rue de la Doua, CS 70077, 69626 VILLEURBANNE Cedex, France.

17 Email: andre.paquier@irstea.fr

18 KOJI SHIONO (IAHR Member), Professor, Department of Civil and Building Engineering, 19 Loughborough University, Leicestershire,UKLE11 3TU, United Kingdom.

20 Email: k.shiono@lboro.ac.uk 


\title{
Turbulent flows in straight compound open-channel with a transverse embankment on the floodplain
}

\begin{abstract}
The present study deals with turbulent flows in an asymmetrical compound channel with an embankment set on the floodplain, perpendicularly to the longitudinal direction. The main purpose of this study was to assess how a rapidly varied flow affects interaction between the floodplain flow and the main channel flow. In addition to rapid changes in the water level and velocity across the compound channel that have a great influence on the boundary shear stress distribution, the embankment, through two recirculation zones developing upstream and downstream, is also responsible for strong lateral mass exchange between the main channel and the floodplains (channel sub-sections). The lateral velocity can indeed reach $50 \%$ of the longitudinal velocity, which modifies the characteristics of the mixing layer developing between the channel sub-sections. Depth-averaged Reynolds shear stresses 5 times greater than those measured for reference flows are recorded within the mixing layer, which indicates that the turbulent exchange is also impacted by the lateral mass exchange.
\end{abstract}

Keywords: Flood modelling, Flow-structure interactions, Laboratory studies, Separated flows, Turbulent mixing layers.

\section{Introduction}

In natural or engineered rivers, the flow is contained in the main channel $(\mathrm{m})$, limited by the river banks, most of the time. During heavy snow melting events or significant rainfalls, the river main channel cannot convey all the runoff and consequently overflows on its adjacent floodplains $(f)$. The resulting flow is identified as a compound channel flow.

Under uniform flow conditions, the fast and deep flow in the main channel interacts with the slow and shallow flow on the floodplains. This results in the formation of a mixing layer at the interface between the sub-sections (the main channel and the floodplains), which transfers momentum due to turbulent exchange between them (Sellin 1964). This turbulent exchange leads to the decrease in the main channel conveyance and to the increase on the floodplain one. Moreover, the overall conveyance of the compound channel is reduced relative to the one of a single channel of same hydraulic radius (Knight and Demetriou 1983, Knight and Hamed 1984).

Knight and Shiono (1990) and Shiono and Knight (1991) showed that for such flow conditions, the depth-averaged Reynolds shear stress representative of the turbulent exchange, $T_{x y}=\left\langle-\rho \overline{u^{\prime} v^{\prime}}\right\rangle \quad\left(u^{\prime}\right.$ and $v^{\prime}$ the horizontal components of the fluctuating velocity, \langle\rangle the 
depth-averaging operator and ${ }^{-}$the time-averaging operator), is maximal at the junction between the sub-sections. They also found that for a given floodplain width, the lateral extent of the high shear region between the channel sub-sections and the maximum of $T_{x y}$, are inversely proportional to the relative flow depth, $H_{r}=H_{f} / H_{m}\left(H_{f}\right.$ and $H_{m}$, the mean water depth on the floodplain and in the main channel respectively), while they increase with the floodplain width and a constant $H_{r}$. According to van Prooijen et al. (2005), the behaviour of $T_{x y}$ within the mixing layer must be linked to the difference in velocity between the subsections, $U_{m}-U_{f}\left(U_{m}\right.$ and $U_{f}$ are the longitudinal mean velocity in the main channel and on the floodplain respectively), and to the lateral gradient of the depth-averaged longitudinal velocity, $\partial U_{d} / \partial y$.

The turbulent exchange between the sub-sections also depends on channel geometries according to results of three types of geometries, which were studied in the past:

- Prismatic geometry with a disequilibrium in the upstream discharge distribution (Bousmar et al. 2005, Proust et al. 2011, 2013),

- Non prismatic geometry with a continuous variation in the floodplain width, the overall width being constant along the channel, as skewed compound channels (Elliot and Sellin 1990, Chlebek and Knight 2008) and compound meandering channels (Shiono and Muto 1998),

- Non prismatic geometry with a variable overall width, as symmetrically converging floodplains (Bousmar et al. 2004), symmetrically diverging floodplains (divergence angle smaller than 5.8 ; Proust 2005, Bousmar et al. 2006) and compound channel with an abrupt floodplain contraction (convergence angle of $22^{\circ}$; Proust et al. 2006).

These flows were defined as gradually varied flows. In these experiments, each channel either yields or receives water from its adjacent channel(s); this exchange of mass, along with nonnegligible lateral velocities, generates noticeable additional lateral exchange of streamwise momentum that superimposes to the turbulent exchange between the sub-sections (Proust et al. 2009, 2010). According to Proust et al. (2013), the direction and the intensity of the lateral velocity induce changes in the lateral distribution of the local Reynolds shear stress, $-\rho \overline{u^{\prime} v^{\prime}}$ $-\rho \overline{u^{\prime} v^{\prime}}$, by stretching the coherent structures that develop inside the mixing layer. When mass is transferred from the floodplain to the main channel, the region of high turbulent shear is displaced towards the main channel. Both the maximum of $T_{x y}$ and the lateral extent of the high shear region are lowered. When mass is transferred towards the floodplains, the high shear region widely extends on the floodplains and the peak of $T_{x y}$ at the sub-sections junction is enhanced.

In natural or manmade rivers, the floodplains may rapidly vary with obstacles either natural (natural levees, rock slide) or artificial (embankments for railways and motorways). 
91 This has various implications for risk assessment and river geomorphology. The considered embankment here acts as an asymmetric, partial dam which causes an elevation of the water depth in the whole upstream channel. The flow on the floodplain is then constricted by the obstacle, which promotes the development of two recirculation zones, one upstream from the obstacle and one downstream. Silting can occur in these slack-flows. Oppositely, the flow has to skirt the embankment and its acceleration, causes scouring and can possibly blow away goods or people. When focusing on the flow description, it results in significant variations of the flow section and in the generation of strong lateral mass exchange (relatively to gradually varied flows) between the sub-sections (Proust 2005, Bourdat 2007, Peltier et al. 2008, 2009). This type of flow commonly occurs in the fields, but has been rarely studied. Among the few studies dealing with overbank flows with an obstacle on the floodplain (Proust 2005, Peltier et al. 2008), the results indicated that 2D-H numerical modelling has some difficulties in capturing the recirculating flows and that the physics of the mixing layers in the channel is still not well understood. Additional detailed measurements of the turbulence characteristics and of boundary shear stress are required, along with some theoretical developments. The understanding of overbank flows in compound channel with a transversal obstacle blocking off the floodplain is indeed paramount for flood modellers. The accurate estimation of the characteristics of the one hundred year return period flood, for instance, is necessary for designing unsinkable motorway and railway embankments (Lefort and Tanguy 2009). Moreover, as part of the establishment of flood hazard prevention plans, flooded area in the vicinity of embankments must be determined with minimal uncertainties.

The present study then aims at assessing the effects on the hydraulic parameters of the superposition of two types of flows: (i) a rapidly varied flow in the vicinity of a thin embankment and (ii) a compound channel flow. We notably estimate the effects of the lateral mass exchange on the interaction between the flows in the sub-sections.

\section{Experimental setup}

\subsection{The compound channel}

The present experiments were conducted in an experimental flume located at the Laboratoire de Mécanique des Fluides et d'Acoustique (LMFA, Lyon, France). The flume has a length, $L$, of $8 \mathrm{~m}$ and a total width, $B$, of $1.2 \mathrm{~m}$. This flume is straight with an asymmetrical crosssection and has a longitudinal bed-slope, $S_{o x}$, of $0.18 \%$. The main channel cross-section is rectangular (Figure 1) and is $0.4 \mathrm{~m}$ wide. The bank-full height, $b$, is of $5.1 \mathrm{~cm}$ and the floodplain is $0.8 \mathrm{~m}$ wide. The floodplain and the main channel are PVC made and their surface state is smooth. 
Following the recommendations of Bousmar et al. (2005), separated inlet tanks for the main channel and the floodplain were installed (see schematic top view in Figure 1). They are used to distribute the required discharges in the sub-sections, which enables to quickly establish a uniform flow relative to in a flume with a single inlet. The flow is then canalised by a succession of grids and the free surface oscillations are attenuated by a float. The outlet consists of two independent adjustable tailgates, one for each sub-section. The separated tailgates enable a better adjustment of the downstream boundary conditions by reducing the backwater effects and the lateral mass exchange between the sub-sections at the far end of the flume.

In the present paper, we use a Cartesian coordinate system in which $x, y$ and $z$ are the longitudinal, lateral and vertical directions, respectively (as presented in Figure 1). $x=0$ immediately downstream from the inlet tanks and $y=0$ at the lateral bank of the floodplain. $z$ is taken along a plan following the mean slope of the flume and obtained by the root mean square method. The origin of the plan is taken in the main channel.

\subsection{Measurements devices}

\section{Water depth and level}

The water depths and the water levels were measured using an ultrasonic probe (Baumer

142 Electric, UNDK 20I $6912 \mathrm{~S} 35 \mathrm{~A})$. The uncertainty of the probe was estimated to $\pm 0.42 \mathrm{~mm}$

143 for a recording time greater than $20 \mathrm{~s}$.

145 A micro-propeller (Nixon, Streamflo Velocity Meter 403) was coupled to a vane and an 146 encoding angle device for simultaneously measuring the flow direction and the mean 147 velocities. The recording time was set to between $60 \mathrm{~s}$ and $90 \mathrm{~s}-$ depending on the lateral 148 position in the flume - to ensure an accurate estimation of the mean and standard deviation of 149 the velocity. With such recording time, the uncertainties were estimated to $1.5 \%$ of the mean 150 velocity.

Measurements of instantaneous velocities were performed using a 2D side-looking

152 Acoustic Doppler Velocimeter (micro-ADV, Nortek, Vectrino+). The sampling frequency 153 was set to $100 \mathrm{~Hz}$ with a signal-to-noise ratio greater than $20 \mathrm{~dB}$ in order to have weak 154 influences of the noise (McLelland and Nicholas 2000). The recording time was set at least to 1553 min to ensure an accurate estimation of the mean and standard deviation of the signal. 

velocities were minimised. The measured velocity signals were despiked using the method of

158 Goring and Nikora (2002) and the probe misalignment was estimated and corrected using the 159 methods presented in Peltier (2011).

The boundary shear stress was measured with a Preston tube (outer diameter of $2.72 \mathrm{~mm}$ ) using the calibration law specified by Patel (1965). For each experiment, the Preston tube was aligned with respect to the longitudinal direction and the uncertainty was within $6 \%$ of the measured boundary shear stress (Preston 1954). In case of large lateral velocities, a correction coefficient was applied to the pressure measurements for taking into account the fact that the Preston is no longer aligned with the main flow direction. The correction coefficient was worked out by measuring the resulting pressure when the Preston tube was turned by a known angle in a uniform flow.

\section{Measurement grid}

The measuring devices were mounted on a movable carriage moving on a metal frame in the vicinity of the flume. This metal frame is independent of the flume and has the same longitudinal mean slope as the flume. The carriage was programmable and was moved through a DC motor with an accuracy of $\pm 0.2 \mathrm{~mm}$ in both $x$ - and $y$-directions.

Along the $y$-axis, the grid-step of the measurements was 5 or $10 \mathrm{~cm}$ from $y=0.05 \mathrm{~m}$ to $y=0.75 \mathrm{~m}, 1 \mathrm{~cm}$ from $y=0.75 \mathrm{~m}$ to $y=0.85 \mathrm{~m}$ (the junction between the sub-sections is at $y=0.8 \mathrm{~m}$ ) and 2.5 or $5 \mathrm{~cm}$ from $y=0.85 \mathrm{~m}$ to $y=1.15 \mathrm{~m}$. The grid-step along the $x$-axis was not regular and depends on the measuring device used. The water depth and the mean velocity were measured at every $0.5 \mathrm{~m}$ from $x=1.5 \mathrm{~m}$ to $x=3.5 \mathrm{~m}$ (the embankment is placed at $x_{e}=2.5 \mathrm{~m}$ ) and then at every $1 \mathrm{~m}$ until the end of the flume. The instantaneous velocity and the boundary shear stress were measured in four cross-sections: one upstream from the embankment at $x=2 \mathrm{~m}$, one in the embankment cross-section at $x=x_{e}=2.5 \mathrm{~m}$ and two downstream from the embankment at $x=4.5 \mathrm{~m}$ and $6.5 \mathrm{~m}$. Along the $z$-axis, the velocity was measured at least at 2 vertical positions on the floodplain for the shallowest case and at 6 vertical positions for the deepest case.

\subsection{Flow conditions}

186 The total discharge and the length of the embankment were chosen in order to examine a 187 large range of flow conditions, with in particular a large mass exchange between sub-sections. 188 In these experiments, the mass exchange was generated by a transverse embankment set on 
the floodplain and the intensity of the lateral mass exchange was inversely proportional to the longitudinal length of the recirculation zones developing on both sides of the embankment (upstream: $L_{x}^{u}$ and downstream: $L_{x}^{d}$ ). The recirculation zones were identified by Large Scale Particle Image Velocimetry (LSPIV); they are bounded by the floodplain wall and the separation streamline corresponding to zero-discharge in the recirculation zone.

The flow conditions are summarized in Table 1. Three reference flows with no embankment were first investigated. The three values of the total discharge, $Q_{t}$, and discharge ratio on the floodplain, $Q_{f} / Q_{t}$, were those to have uniform flows with the relative flow depths $H_{r}=0.2,0.3$ and 0.4 , respectively. The downstream tailgates were adjusted so that the mean slope of the water surface was equal to the longitudinal bed-slope. Six flows with a thin obstacle, representing an embankment on the floodplain, were further investigated. The embankment was set at $x_{e}=2.5 \mathrm{~m}$, perpendicularly to the longitudinal direction. Various lengths of embankment, $d$, were investigated (see the fourth column in Table 1), with the boundary conditions used for the reference flows, i.e. the same upstream discharge distributions and height of the tailgates.

To analyse the flow conditions, we first consider the longitudinal lengths of the recirculation zones that develop upstream $\left(L_{x}^{u}\right)$ and downstream $\left(L_{x}^{d}\right)$ from the embankment (see the fifth and sixth columns in Table 1). $L_{x}^{u}$ is close to $d$ for the upstream recirculation zone and the lateral extent $L_{\mathrm{y}}(x)$ is never larger than $d$. By contrast, $L_{x}^{d}$ increases with the total discharge and the embankment length, and the lateral extent $L_{\mathrm{y}}(x)$ of the downstream recirculation zone can reach $1.1 \times d$ between $x=2.75 \mathrm{~m}$ and $x=3.25 \mathrm{~m}$ for the six flow-cases with an embankment (not shown in Table 1). This generates a constricted cross-section in the flow. Regarding the normalised length $L_{x}^{d} / d$, it decreases with increasing $d / B_{f}$ or decreasing $Q_{t}$, therefore emphasising the role of the bed-generated turbulence in the development of the recirculation zone (Chu et al. 2004, Rivière et al. 2004, 2011). Considering the Reynolds number in the sub-sections, $\mathrm{R}_{\mathrm{i}}=4 R_{i} U_{i} / \nu$ ( $v$ the kinematic viscosity, $U_{i}$ and $R_{i}$ respectively the mean velocity and the hydraulic radius in a subsection), the values in the main channel are one order of magnitude greater than those on the floodplain (see seventh and eight columns in Table 1). However, the Reynolds numbers in both sub-sections are sufficiently high to neglect viscosity effect in the computation of the stresses. Finally the minimal and the maximal relative flow depths (last column in Table 1) indicate very weak longitudinal variations in the flow depth for the reference flows, while significant variations are observed for the flowcases with an embankment: for such flow conditions, the depth on the floodplain can be twice higher than that measured without an embankment. 
In the following sections, the flow-cases are referenced in the form $Q / d$, where $Q$ is the total discharge and $d$ the embankment length. Reference cases have $d=0.0$ (see in Table 1).

\section{A rapidly varied flow}

In this section, we show how the embankment set on the floodplain generates a rapidly varied flow on the floodplain and in a lesser extent in the main channel.

\subsection{Water depth and level}

The left plots in Figure 2 show the longitudinal variations in the floodplain water depth, $H_{f}$. Putting aside the most downstream position and the three first meters for flow-case 17.3/0.0, a constant flow depth (to the uncertainty) is observed in the flume for the reference flows. The increase in depth at the end of the flume is due to a slight backwater effect caused by the difference in level between the bottom of the flume and the bottom of the tailgates. Regarding the decrease in depth at the inlets (particularly marked for 17.3/0.0), it is due to the grids in the reservoir that induce a strong head loss and a plunging flow at the channel entrance. For the embankment-cases, the embankment induces strong variations in the water depth and the distortions (relative to the reference flows) are felt until the end of the flume. On the floodplain near the embankment the longitudinal mean slope of the free surface, $S_{w x}$, is one order of magnitude greater than the longitudinal mean slope of the bed $\left(S_{o x}=0.18 \%\right)$ and the steepness of this slope increases with both the embankment length $\left(S_{w x} \approx 1.5 \%\right.$ for $24.7 / 0.3$ and $S_{w x} \approx 3 \%$ for $\left.24.7 / 0.5\right)$ and the total discharge $\left(S_{w x} \approx 1 \%\right.$ for $17.3 / 0.3$ and $S_{w x} \approx 4 \%$ for $36.2 / 0.3)$. It is interesting to see that the water depth at the end of the flume is equivalent to the uniform one for most flows with an embankment. This seems to indicate that, in our short flume, the recirculation is hardly affected by any backwater effects coming from the downstream condition, though a uniform lateral velocity profile is not recovered.

The lateral distribution of the water level, $Z$, is shown in four cross-sections in Figure 2 (right plots) for flow-cases $24.7 / 0.3,24.7 / 0.5$ and $36.2 / 0.3$. The lateral mean slope of the free surface, $S_{w y}$, can be of the same order of magnitude as $S_{o x}$ in the zone of large lateral velocities. This slope increases with both the embankment length $\left(S_{w y} \approx 0.25 \%\right.$ for $24.7 / 0.3$ and $S_{w y} \approx 1 \%$ for $\left.24.7 / 0.5\right)$ and the total discharge $\left(S_{w y} \approx 0.2 \%\right.$ for $17.3 / 0.3$ and $S_{w y} \approx 0.8 \%$ for 36.2/0.3). A transverse flow is observed from high water level areas to low water areas, except at $x=4.5 \mathrm{~m}$ for $36.2 / 0.3$, where the presence of a normal undulated hydraulic jump at this station makes locally rise the water level (see subsection 3.3). 


\subsection{Depth-averaged velocity}

Figure 3 shows the 2D fields of the longitudinal and lateral depth-averaged velocities $\left(U_{d}, V_{d}\right)$. The embankment and the resulting recirculation zones (Table 1) are responsible for large variations in the flow section, therefore leading to significant lateral depth-averaged velocities $V_{d}$. In the vicinity of the embankment tip, $V_{d}$ can be up to $50 \%$ of the longitudinal depthaveraged velocities $U_{d}$. The flow in the main channel is less influenced by the obstacle and $V_{d}$ is rather close to $10 \%$ of $U_{d}$. The sign of $V_{d}$ must be referenced relative to the contracted cross-section located between $x=2.75 \mathrm{~m}$ and $x=3.25 \mathrm{~m}$ (where $L_{\mathrm{y}}(x)=1.04-1.1 \times d$ see in Figure 3): upstream from the contraction, the lateral velocities are positive and the flow converges from the floodplain towards the main channel; downstream, the flow diverges from the main channel towards the floodplain.

The comparison of the distribution of the longitudinal depth-averaged velocity with the reference flow emphasises that as long as a recirculation zone is present in the measurement cross-section the velocity difference, $U_{m}-U_{f}$, decreases while the maximum of the velocity gradient within the mixing layer, $\partial U_{d} / \partial y$, increases. Indeed $\partial U_{d} / \partial y$ also depends on the width of the mixing layer that develops between the channel sub-sections. This width is also modified by the embankment, as shown in section 4 .

\subsection{Froude number}

A typical distribution of the local Froude number, $\mathrm{F}=\sqrt{U_{d}^{2}+V_{d}^{2}} / \sqrt{g h}$ ( $h$ the local water depth), is presented in Figure 4 (flow-case 24.7/0.3). Because of the large velocities (see in Figure 3) and the relatively low water depths on the floodplain (see $H_{f}$ in Figure 2), Froude numbers higher than 0.5 are found for all flow-cases with the embankment. Moreover, the flow becomes supercritical from the contraction until at least the half of the downstream recirculation zone. This supercritical zone expands with both the total discharge and the embankment length. The transition from the supercritical to the subcritical regime is operated through a normal undulated jump consistent with the maximal Froude number smaller than 1.7 (Graf and Altinakar 2000). By contrast, the flow in the main channel is always subcritical.

\subsection{Lateral mass exchange}

Figure 5(a) shows the longitudinal variation in the floodplain discharge compared to that for the reference flows, $100 \times\left(Q_{f}-Q_{f}^{r e f}\right) / Q_{f}^{r e f}$. The exchange of mass between the sub-sections occurs until the end of the flume for each case and the longitudinal variation in the floodplain discharge increases with the embankment length, but decreases with the total discharge. The minimal floodplain discharge is reached near the contracted cross-section: the floodplain can 
here lose up to $65 \%$ of its discharge (flow-case 24.7/0.5).

To get a deeper insight into the lateral mass exchange, the Figure 5(b) shows the longitudinal variations in the normalised intensity of the lateral mass exchange per unit length:

$$
q_{n}=-\frac{\mathrm{d} Q_{f}}{Q_{f}}
$$

defined at the junction between the sub-sections (a mass exchange from the floodplain towards the main channel corresponds to $q_{n}>0$ ). In the present experiments, the maximum of $q_{n}$ ranges from 0.2 to 0.8 , while for non-uniform flows in a straight compound channel, it does not exceed 0.2 for the most extreme case (Proust et al. 2011, 2013): the initial objective of working with larger mass exchanges is then achieved. The strongest exchanges are observed in the cross-sections near the embankment and the absolute value of $q_{n}$ increases with the embankment length. By contrast, given the uncertainty on the computation of $q_{n}$ ( $\delta q_{n}= \pm 0.07$ ), it seems that the total discharge has little effect on the variations of $q_{n}$.

\subsection{Time-averaged local velocity}

The time-averaged longitudinal velocity, $\bar{u}$, is displayed in Figure 6 for the flow-case 24.7/0.0 at $x=5.5 \mathrm{~m}$ (where the reference flow is almost established; Peltier 2011) and for the flow-cases $24.7 / 0.5$ at $x=2 \mathrm{~m}$ (upstream from the embankment), $x=2.5 \mathrm{~m}$ (in the embankment cross-section) and $x=4.5 \mathrm{~m}$ (downstream from the embankment). Notice that missing data in some of the contour plots in Figure 6, is due to the metrological considerations: intrusive device and low water depths in some cross-sections. Regarding the flow-case 24.7/0.0, the inflection of the isovels in the main channel clearly emphasises the presence of secondary currents of Prandtl's second kind (Tominaga and Nezu 1991). These secondary current cells are due to the presence of the two vertical solid boundaries in the main channel. By contrast, the presence of secondary current cells for the flow-cases with an embankment is not so clear. The lateral mass exchange between the channel sub-sections is responsible for the weakening of these structures. In the case of the lateral mass exchange from the floodplain towards the main channel (flow-case 24.7/0.5 at $x=2 \mathrm{~m}$ and $x=2.5 \mathrm{~m}$ in Figure 6), some slow water enters the upward part of the main channel until the centreline (above the bank-full level) and also the downwards part of the main channel near the floodplain edge, which destroy the secondary currents. The penetration of this slow flow, is obviously proportional to $q_{n}$ (see Figure 5). In the case of the lateral mass exchange coming from the main channel towards the floodplain (flow-case 24.7/0.5 at $x=4.5 \mathrm{~m}$ in Figure 6), the flow in the main channel and on the floodplain is homogenised by the mass exchange and 
only boundary layers at the walls can be observed. Once the reattachment point of the downstream recirculation zone is reached and $q_{n}$ is close to zero, the flow in both sub-section starts establishing a typical compound channel flow.

\section{Interaction between a rapidly varied flow and a compound channel flow}

In this section, we discuss how the parameters usually studied in compound channel flows are affected by the lateral mass exchange induced by the embankment on the floodplain.

\subsection{Boundary shear stress}

Figure 7 first shows typical distributions of boundary shear stress, $\tau_{b}$, measured under uniform flow conditions with no embankment on the floodplain (at $x=4.5 \mathrm{~m}$ ). The boundary shear stress on the floodplain is always smaller than that in the main channel and it increases with the total discharge. The changes in $\tau_{b}$ are smaller in the main channel, since the changes in the velocity are smaller in the main channel than in the floodplain.

Figure 7 then shows $\tau_{b}$ for the flow-cases with the embankment 24.7/0.3, 24.7/0.5 and 36.2/0.3. The boundary shear stress on the floodplain at $x=2 \mathrm{~m}$ (upstream from the embankment and $q_{n}>0$ ) decreases compared to those measured for reference flows, because of the rise in the water depth and of the flow deceleration. This decrease is even larger when the embankment length is longer or the discharge is higher. By contrast, in the embankment cross-section, at $x=2.5 \mathrm{~m}$, the boundary shear stress rapidly increases, as the flow here is plunging and is strongly accelerated close to the bottom. Downstream from the embankment where $q_{n}<0$, the boundary shear stresses measured at $x=4.5 \mathrm{~m}$ and $x=6.5 \mathrm{~m}$ out of the downstream recirculation zone can be $375 \%$ greater than those measured on the floodplain under uniform flow conditions. These changes are due to the strong flow acceleration and the very shallow flow related to the supercritical flow regime (Figure 4). It can be noticed that the distribution of boundary shear stress on the floodplain does not coincide with the referenceflow one as long as the downstream recirculation zone has not reattached (see flow-cases $36.2 / 0.0$ and $36.2 / 0.3$ at $x=6.5 \mathrm{~m}$ in Figure 7).

\subsection{Mixing layer between the sub-sections}

$U_{1}$ and $U_{2}$ are the mean longitudinal velocities worked out with the depth-averaged velocities located in the outside of the mixing layer in the main channel and in the floodplain respectively. We can define the lateral location $y_{\alpha}(x)$ for $0<\alpha<1$ such that the longitudinal depth-averaged velocity, $U_{d}$, writes:

$$
U_{d}\left(x, y_{\alpha}(x)\right)=U_{2}+\alpha\left(U_{1}-U_{2}\right)
$$


The width of the mixing layer, $\delta(\mathrm{x})$, can be defined as follows (van Prooijen et al. 2005):

$$
\delta(x)=2\left(y_{0.75}(x)-y_{0.25}(x)\right)
$$

and the centre of the mixing layer, $y_{c}$, is defined as being equal to $y_{0.5}$.

The Figure 8(a) shows the longitudinal variations in the mixing layer width, $\delta(\mathrm{x})$, for the embankment-cases, compared to the width, $\delta^{\text {ref }}(x)$, of the reference flows. As long as the recirculation zone is present in the measurement cross-section (from $x \approx x_{e}-L_{x}^{u}$ until $\left.x \approx x_{e}+L_{x}^{d}\right), \delta(\mathrm{x})$ is smaller than $\delta^{r e f}(x)$, because the velocity difference, $U_{m}-U_{f}$ (see in Figure 3), is smaller than that for the reference flows (not shown here); e.g. the flow contraction induces an increase in the floodplain velocity higher than the increase in the main channel velocity. Upstream and downstream from this zone, $\delta(\mathrm{x})$ is either equivalent to $\delta^{\mathrm{ref}}(\mathrm{x})$ or greater, because $U_{m}-U_{f}$ is equal or greater than for the reference flow.

The Figure $8(\mathrm{~b})$ then shows that the centre of the mixing layer, $y_{c}(x)$, does not always follow the geometrical forcing created by the floodplain edge. On the one hand, $y_{c}(x)$ is shifted in the main channel when the normalised intensity of the lateral mass exchange per unit length $q_{n}>0$ and the shift is proportional to $q_{n}$. On the other hand, it seems to remain on the floodplain edge for $q_{n}<0$ as observed by Proust $e t$ al. (2013) in a straight compound channel with a similar value of $q_{n}$.

The shape of the mixing layers that develop in the flow-cases 24.7/0.0, 24.7/0.3 and 24.7/0.5 are displayed in Figure 8(c). The part of the mixing layer on the floodplain is highly impacted by the lateral mass exchange and for the most extreme cases (see flow-case 24.7/0.5), the mixing layer can even disappear where $q_{n}$ is maximum.

\subsection{Reynolds shear stress}

The Figure 9(a) shows the lateral distribution of the depth-averaged Reynolds shear stress, $T_{x y}$, for the three reference-cases at the downstream position $x=5.5 \mathrm{~m}$, where the flows were established in term of water depth and longitudinal depth-averaged velocity. The lateral extent of the high shear region between the channel sub-sections is close to $\delta^{\text {ref }}(x)$ (not shown here) and as observed in the literature for vertical banks, the maximum of $T_{x y}$ is located at the subsections' junction. The magnitude of the maximum of $T_{x y}$ is inversely proportional to the relative flow depth $H_{r}$ and is proportional to the velocity difference between the sub-sections $U_{m}-U_{f}: \max \left(T_{x y}\right)=1.28 \mathrm{~Pa}$ and $0.57 \mathrm{~Pa}, U_{m}-U_{f}=0.33 \mathrm{~m} \mathrm{~s}^{-1}$ and $0.17 \mathrm{~m} . \mathrm{s}^{-1}$, and $H_{r}=0.2$ and 0.4 for cases 17.3/0.0 and 36.2/0.0 respectively. These results confirm the relationship between $T_{x y}$ and $H_{r}$ under uniform flow conditions with a constant floodplain width (Shiono and Knight 1991). 
The lateral distribution of the depth-averaged Reynolds shear stress, $T_{x y}$, is strongly correlated to the lateral gradient of the depth-averaged longitudinal velocity, $\partial U_{d} / \partial y$. Figure 9(b-d) put into relation $T_{x y}$ and $\partial U_{d} / \partial y$ for the reference flow-cases. $\partial U_{d} / \partial y$ is multiplied by a calibrated constant turbulent eddy viscosity, $v_{t}$, equal to $0.3 \times 10^{-3} \mathrm{~m}^{2} \mathrm{~s}^{-1}$ in order to respect the dimension of $T_{x y}$. The lateral variations in both parameters are similar, therefore qualitatively confirming the Boussinesq relationship for the reference flows.

The lateral profiles of $T_{x y}$ for the flow-cases 24.7/0.3, 24.7/0.5 and 36.2/0.3 are displayed in Figure 10 at various locations along the channel. Similarly to the reference flows (Figure 9(a)), the position of the maximum of $T_{x y}$ coincides with $y_{c}(x)$ (see in Figure 8(b)). By contrast, the magnitudes of the maximum of $T_{x y}$ can be 3 or 5 times greater or smaller than those measured for the reference flows. It can be noticed that a secondary maximum is also observed on the floodplain downstream from the embankment (see at $x=4.5 \mathrm{~m}$ for $24.7 / 0.5$ in Figure 10(c)) and exists as long as the downstream recirculation has not reattached. This secondary maximum is due to the mixing layer that develops between the recirculation zone and the main flow.

The lateral extent of the high shear region also coincides with the one of $\delta(x)$. When $q_{n}>0$ (Figure 10(a)), the lateral extent reduces with an increase in the embankment length or in the total discharge. By contrast, when $q_{n}<0$, the variations in the lateral extent are not so clear (see at $x=4.5 \mathrm{~m}$ in Figure 10(c)), because the second mixing layer that develops between the downstream recirculation zone and the main flow constrains the floodplain flow and prevents the mixing layer between the sub-sections from spreading too far on the floodplain.

All the modifications undergone by the turbulent exchange within the mixing layer are due to the changes imposed by the lateral mass exchange to the distribution of the longitudinal velocity in the flume. The right plots in Figure 10 show the lateral distribution of the depth-averaged longitudinal velocity, $U_{d}$, in the same cross-sections as those for $T_{x y}$. As shown in Figure 10(a-b: upstream and in the embankment cross-section), the lateral extent of the high shear region is proportional to the velocity gradient, $\partial U_{d} / \partial y$, and the maximum of $T_{x y}$ is proportional to $U_{m}-U_{f}$. When considering the stations downstream from the embankment (see at $x=4.5 \mathrm{~m}$ in Figure 10(c)), the lateral extents of the high shear region can be smaller than that measured upstream from the embankment although $\partial U_{d} / \partial y$ is the same (flow-case 24.7/0.3). This is due to the presence of the velocity dip in the distribution of $U_{d}$ observed from the contraction to at least the half of the downstream recirculation (i.e. while both mixing layers can interact). Finally, the very large peak of Reynolds stress at the sub- 
sections' junction at $\mathrm{x}=4.5 \mathrm{~m}$ for case $24.7 / 0.5$, which is related to an almost discontinuity of velocity, highlights an extremely high turbulent diffusion that can lead to bank erosion.

\section{Conclusion}

The present paper investigates experiments in a compound open-channel with a transverse embankment on the floodplain. The embankment creates a rapidly varied flow on the floodplain, which subsequently interacts with the flow in the main channel. Each varied flow is compared to the reference flow obtained under uniform flow conditions in the same flume.

The embankment and the recirculation zones that develop upstream and downstream are responsible for a strong lateral mass exchange, which induces significant changes in the water depth and the velocity distribution across the compound channel, when compared to the reference flows. The mean slopes of the free surface (lateral and longitudinal) can be one order greater than the mean bed-slope and the lateral depth-averaged velocity near the embankment can reach $50 \%$ of the longitudinal depth-averaged velocity. Moreover, because of the low water depth and the high velocity on the floodplain downstream from the embankment, a supercritical flow occurs until at least the half length of the downstream recirculation zone.

These changes have also great impacts on the parameters more specific to compound channel flows. It confirms the implication for flood risk assessment and geomorphology mentioned in the introduction. While the increase in water depth can reach about 50\% in the floodplain upstream the embankment, the 3D flow at the tip of the embankment and the acceleration in the supercritical zone downstream, induce boundary shear stresses up to $375 \%$ greater than those of the reference flows. The mixing layer developing at the interface between the sub-sections is also highly affected by the embankment, the recirculation zones and the lateral mass exchange. As long as a recirculation zone is present in the measurement cross-section, the mixing layer width remains smaller than the reference flows one and the turbulent exchange (i.e. depth-averaged Reynolds shear stress) is strongly affected. The magnitude of the peak of depth-averaged Reynolds shear stress can be up to 5 times greater than that for the reference flows, while the lateral extent of the high shear region is $100 \%$ smaller. The peak is besides not always located at the junction: it is shifted in the main channel when mass is transferred from the floodplain towards the main channel and remains at the sub-sections' junction in the opposite direction. Nevertheless, the Boussinesq hypothesis can still be used in first approach for describing the evolution of the high shear region. 

stress), further work could be devoted to numerically model such rapidly varied compound channel flows in 1D and 2D-H (Linde et al. 2012).

- Concerning 1D modelling, the description of the turbulent exchange at the interface between the sub-sections is paramount for calculating the discharge distribution between sub-sections. The present results are of interest to modellers for improving its modelling, since for now only the shear at the interface between the sub-sections is considered (apparent shear stress, mixing length model...), and assumed to be maximum (Nicollet and Uan 1979, Proust et al. 2009).

- Concerning 2D modelling, we showed that the Boussinesq hypothesis is still valid for flows with embankment, which is interesting for low-cost modelling in an operational point of view. We also highlighted the behaviour of the secondary currents in the presence of an embankment, which could be used to correct the shallow water equations by adding terms taking into account the dispersion on the vertical of the horizontal velocities (Peltier 2011).

Acknowledgements

The research was funded by IRSTEA and by the Rhône-Alpes region (SRESR advices.

\section{Notation}

$b=$ Bank-full height (m)

$B=$ Total width of the flume (m)

$B_{f}=$ Width of the floodplain (m)

$B_{m}=$ Width of the main channel (m)

$\mathrm{F}=$ Froude number $(-)$

$482 g=$ Gravity constant $\left(\mathrm{m} \cdot \mathrm{s}^{-2}\right)$

$483 h=$ Local water depth (m)

$484 \quad H_{f}=$ Water depth on the floodplain (m)

$485 \quad H_{m}=$ Water depth in the main channel (m)

$486 \quad H_{r}=$ Relative flow depth (-)

$487 L=$ Longitudinal length of the flume (m)

$L_{x}^{d}=$ Longitudinal length of the downstream recirculation zone (m) 
$L_{x}^{u}=$ Longitudinal length of the upstream recirculation zone (m)

$L_{\mathrm{y}}(x)=$ Lateral extent of the recirculation zones $(\mathrm{m})$

$491 q_{n}=$ Normalised intensity of lateral mass exchange per unit length (-)

$492 Q_{f}=$ Discharge on the floodplain $\left(\mathrm{m}^{3} \cdot \mathrm{s}^{-1}\right)$

$Q_{t}=$ Total discharge $\left(\mathrm{m}^{3} \cdot \mathrm{s}^{-1}\right)$

$R_{i}=$ hydraulic radius of sub-section $i(\mathrm{~m})$

$\mathrm{R}=$ Reynolds number (-)

$S_{o x}=$ Longitudinal mean bed-slope (-)

$497 S_{w x}=$ Longitudinal mean free surface slope (-)

$498 \quad S_{w y}=$ Lateral mean free surface slope (-)

$499 T_{b i}=$ Mean boundary shear stress in the sub-section $i(\mathrm{~Pa})$

$500-\rho \overline{u^{\prime} v^{\prime}}=$ Reynolds shear stress $(\mathrm{Pa})$

$501 \quad T_{\mathrm{xy}}=$ Depth-averaged Reynolds shear stress $(\mathrm{Pa})$

$502 \bar{u}=$ Time-averaged longitudinal velocity $\left(\mathrm{m}^{-1} \mathrm{~s}^{-1}\right)$

$503 u=$ Fluctuating longitudinal velocity $\left(\mathrm{m}^{\mathrm{m}} \mathrm{s}^{-1}\right)$

$504 U_{d}=$ Longitudinal depth-averaged velocity $\left(\mathrm{m} . \mathrm{s}^{-1}\right)$

$505 U_{f}=$ Longitudinal mean velocity on the floodplain $\left(\mathrm{m} \cdot \mathrm{s}^{-1}\right)$

$506 U_{m}=$ Longitudinal mean velocity in the main channel $\left(\mathrm{m} . \mathrm{s}^{-1}\right)$

$507 \quad v^{\prime}=$ Fluctuating lateral velocity $\left(\mathrm{m} . \mathrm{s}^{-1}\right)$

$508 V_{d}=$ Lateral depth-averaged velocity $\left(\mathrm{m} . \mathrm{s}^{-1}\right)$

$509 x=$ Longitudinal direction $(\mathrm{m})$

$510 x_{e}=$ Position of the embankment with respect to the inlets (m)

$511 y=$ Lateral direction $(\mathrm{m})$

$512 y_{c}=$ Centre of the mixing layer between the sub-sections (m)

$513 z=$ Vertical direction $(\mathrm{m})$

$514 \delta(x)=$ Width of the mixing layer between the sub-sections (m)

$515 \quad v=$ Kinematic viscosity $\left(\mathrm{m}^{-2} \cdot \mathrm{s}^{-1}\right)$

$516 \quad v_{t}=$ Turbulent eddy viscosity $\left(\mathrm{m} . \mathrm{s}^{-2}\right)$

$517 \rho=$ Fluid density $\left(\mathrm{kg} \cdot \mathrm{m}^{-3}\right)$

$518 \tau_{b}=$ Boundary shear stress $(\mathrm{Pa})$.

\section{References}

Bourdat, A. (2007). Débordements des cours d'eau en présence de remblais routiers dans les lits majeurs. Master's thesis. HHLY, Cemagref, France. 
Bousmar, D., Wilkin, N., Jacquemart, J. H. and Zech, Y. (2004). Overbank flow in symmetrically narrowing floodplains. J. Hydraulic Eng. 130(4), 305-312.

Bousmar, D., Rivière, N., Proust, S., Paquier, A., Morel, R. and Zech, Y. (2005). Upstream discharge distribution in compound channel flumes. J. Hydraulic Eng. 131, 408-412.

Bousmar, D., Proust, S. and Zech, Y. (2006). Experiments on the flow in a enlarging compound channel. In River Flow 2006: $3^{\text {rd }}$ International Conference on Fluvial Hydraulics. 6-8 September, Lisbon, Portugal.

Chlebek, J., and Knigtht, D. W. (2008). Observations on flow in channels with skewed floodplains. In River Flow 2008: $4^{\text {th }}$ International Conference on Fluvial Hydraulics. 35 September 2008, Cesme-Izmir, Turkey.

Chu, V. H., Liu, F. and Altai, W. (2004). Friction and confinement effects on a shallow recirculating flow. J. Envir. and Eng. Sciences. 3, 463-475.

Elliot, S. C. A. and Sellin, R. H. J. (1990). Serc flood channel facility: skewed flow experiments. J. Hydraulic Res. 28(2), 197-214.

Goring, D. G., and Nikora, V. I. (2002). Despiking acoustic doppler velocimeter data. J. Hydraulic Eng. 128(1), 117-126.

Graf, W. H., and Altinakar, M. S. (2000). Hydraulique fluviale: écoulement et phénomènes de transport dans les canaux à géométrie simple. PPUR presses polytechniques.

Hauet, A., Kruger, A., Krajewski, W. F., Bradley, A., Muste, M., Creutin, J. D. and Wilson, M. (2008). Experimental system for real-time discharge estimation using an imagebased method. J. Hydrologic Eng. 13(2), 105-110.

Knight, D. W., and Demetriou, J. D. (1983). Floodplain and main channel flow interaction. J. Hydraulic Eng. 109(8), 1073-1092.

Knight, D. W., and Hamed, M. E. (1984). Boundary shear in symmetrical compound channels. J. Hydraulic Eng. 110 (10), 1412-1430.

Knight, D. W., and Shiono, K. (1990). Turbulence measurements in as shear layer region of a compound channel. J. Hydraulic Res. 28(2), 175-196.

Lefort, P. and Tanguy, J. M. (2009). Mécanisme de l'écoulement à surface libre. In De la goutte de pluie jusqu'à la mer: traité d'hydraulique environnementale. Tome 1: processus hydrologiques et fluviaux. J. M. Tanguy, eds. Lavoisier, Paris, France, 207265.

Linde, F., Paquier, A., Proust, S., and Peltier, Y. (2012). Errors in 2-D modelling using a 0th order turbulence closure for compound channel flows. In River Flow 2012: $6^{\text {th }}$ Int. Conf. on Fluvial Hydraulics. 5-7 September, San José, Costa-Rica. 247-254.

McLelland, S. J., and Nicholas, A. P. (2000). A new method for evaluating errors in highfrequency ADV measurements. Hydrological Processes. 14, 351-366. 
Nezu, I., Onitsuka, K. and Iketani, K. (1999). Coherent horizontal vortices in compound open channel flows. In Hydraulic modeling. V. P. Singh, I. W. Seo and J. H. Sonu eds. Water Resources Publications, Colorado, USA, 17-32.

Nicollet, G., and Uan, M. (1979). Ecoulements permanents à surface libre en lit composés. La Houille Blanche. pp. 21-30.

Patel, V. C. (1965). Calibration of the Preston tube and limitations on its use in pressure gradients. J. Fluid Mech. 23, 185-208.

Peltier, Y. (2011). Physical modelling of overbank flows with a groyne set on the floodplain, Ph. D. thesis. Université de Lyon, Lyon, France.

Peltier, Y., Proust, S., Bourdat, A., Thollet, F., Rivière, N. and Paquier, A. (2008). Physical and numerical modelling of overbank flow with a groyne on the floodplain. In River Flow 2008: $4^{\text {th }}$ Int. Conf. on Fluvial Hydraulics. 3-5 September 2008, Cesme-Izmir, Turkey.

Peltier, Y., Proust, S., Thollet, F., Rivière, N. and Paquier, A. (2009). Measurement of momentum transfer caused by a groyne in compound channel. In $33^{\text {rd }}$ IAHR Congress: Water Engineering for a Sustainable Environment. 9-14 August 2009, Vancouver, Canada.

Preston, J. H. (1954). The determination of turbulent skin frictions by means of pitot tubes. J. Royal Aero. Society, 58, 109-121.

Proust, S. (2005). Ecoulements non-uniformes en lits composés : effets de variations de largeur du lit majeur. Ph. D. thesis. INSA de Lyon, Lyon, France.

Proust, S., Rivière, N., Bousmar, D., Paquier, A., Zech, Y. and Morel, R. (2006). Flow in compound channel with abrupt floodplain contraction. J Hydraulic Eng. 132(9), 958970.

Proust, S., Bousmar, D., Rivière, N., Paquier, A. and Zech, Y. (2009). Non-uniform flow in compound channel: a 1D method for assessing water level and discharge distribution, Water Resour. Res. 45(12), 411-424.

Proust, S., Bousmar, D., Rivière, N., Paquier, A. and Zech, Y. (2010). Energy losses in compound open channels. Adv. Water Res. 33(1), 1-16.

Proust, S., Peltier, Y., Fernandes, J. N., Leal, J. B., Thollet, F., Lagouy, M. and Rivière, N. (2011). Effect of different inlet flow conditions on turbulence in a straight compound open channel. In $34^{\text {th }}$ IAHR Congress: Balance and Uncertainty; Water in a Changing World. 26 June-01 July 2011, Brisbane, Australia.

Proust, S., Fernandes, J. N., Peltier, Y., Leal, J. B., Rivière, N. and Cardoso, A. H. (2013). Turbulent non-uniform flows in straight compound open-channels. Submitted to J. Hydraulic Res. 
Rivière, N., Proust, S. and Paquier, A. (2004). Recirculating flow behind groynes for compound channel geometries. In River Flow 2004: $2^{\text {nd }}$ Int. Conf. on Fluvial Hydraulics. 23-25 june 2004, Napoly, Italy.

Rivière, N., Gautier, S. and Mignot, E. (2011). Experimental characterization of flow reattachment downstream open channel expansions. In $34^{\text {th }}$ IAHR Congress: Balance and Uncertainty; Water in a Changing World. 26 June-01 July 2011, Brisbane, Australia.

Sellin, R. H. J. (1964). A laboratory investigation into the interaction between the flow in the channel of a river and that over its flood plain. La Houille Blanche. 793-802.

Shiono, K., and Knight, D. W. (1991). Turbulent open channel flows with variable depth across the channel. J Fluid Mech. 222, 617-646.

Shiono, K., and Muto, Y. (1998). Complex flow mechanisms in compound meandering channels with overbank flows. J. Fluid Mech. 376, 221-261.

Tominaga, A., and Nezu, I. (1991). Turbulent structure in compound open channel flow. J. Hydraulic Eng. 117(1), 21-41.

van Prooijen, B. C., Battjes, J. A., and Uijttewaal, W. S. J. (2005). Momentum exchange in straight uniform compound channel flow. J. Hydraulic Eng. 131(3), 175-183. 
622 Table 1 Main characteristics of the experimental data-set: reference flows (noted $Q / 0.0$ ), 623 embankment-cases (noted $Q / d$ )

\begin{tabular}{|c|c|c|c|c|c|c|c|c|}
\hline & $\begin{array}{c}Q_{t} \\
\left(\mathrm{~L} . \mathrm{s}^{-1}\right)\end{array}$ & $\begin{array}{c}Q_{f} / Q_{\mathrm{t}} \\
(\%)\end{array}$ & $\begin{array}{c}d / B_{f} \\
(-)\end{array}$ & $\begin{array}{c}L_{x}^{u} / d^{\mathrm{a}} \\
\quad(-)\end{array}$ & $\begin{array}{c}L_{x}^{d} / d \\
(-)\end{array}$ & $\begin{array}{c}\mathrm{R}_{\mathrm{f}}^{\mathrm{b}} \\
10^{4}(-)\end{array}$ & $\begin{array}{c}\mathrm{R}_{\mathrm{m}}{ }^{\mathrm{b}} \\
10^{5}(-)\end{array}$ & $\begin{array}{c}H_{r}{ }^{c} \\
(-)\end{array}$ \\
\hline $17.3 / 0.0$ & 17.3 & 13.9 & 0 & 0 & 0 & $1.05-1.22$ & $1.10-1.15$ & $0.21-0.23$ \\
\hline $24.7 / 0.0$ & 24.7 & 25.5 & 0 & 0 & 0 & $2.82-3.15$ & $1.32-1.40$ & $0.32-0.35$ \\
\hline $36.2 / 0.0$ & 36.2 & 38.7 & 0 & 0 & 0 & $6.36-6.75$ & $1.65-1.73$ & $0.41-0.43$ \\
\hline $17.3 / 0.3$ & 17.3 & 13.9 & 0.38 & 1 & 6 & $1.06-1.73$ & $1.13-1.20$ & $0.14-0.23$ \\
\hline $17.3 / 0.5$ & 17.3 & 13.9 & 0.63 & 1 & 5 & $1.16-2.34$ & $1.21-1.31$ & $0.12-0.3$ \\
\hline $24.7 / 0.3$ & 24.7 & 25.5 & 0.3 & 1 & 9.8 & $2.72-3.78$ & $1.26-1.42$ & $0.23-0.38$ \\
\hline $24.7 / 0.5$ & 24.7 & 25.5 & 0.63 & 1 & 8.3 & $2.18-4.79$ & $1.24-1.62$ & $0.21-0.45$ \\
\hline $36.2 / 0.2$ & 36.2 & 38.7 & 0.25 & 1 & 15.25 & $6.18-7.47$ & $1.63-1.87$ & $0.31-0.5$ \\
\hline $36.2 / 0.3$ & 36.2 & 38.7 & 0.38 & 1 & 12.5 & $5.20-7.50$ & $1.69-1.92$ & $0.29-0.54$ \\
\hline
\end{tabular}
(Hauet et al. 2008) using video-sequences of at least 2 min long.

$626{ }^{\mathrm{b}}$ Minimum and maximum Reynolds number in the main channel and on the floodplain between $62.7 x=1.5 \mathrm{~m}$ and $x=7.5 \mathrm{~m}$.

$623{ }^{\mathrm{c}}$ Minimum and maximum relative flow depth between $x=1.5 \mathrm{~m}$ and $x=7.5 \mathrm{~m}$.

624

620

621

627

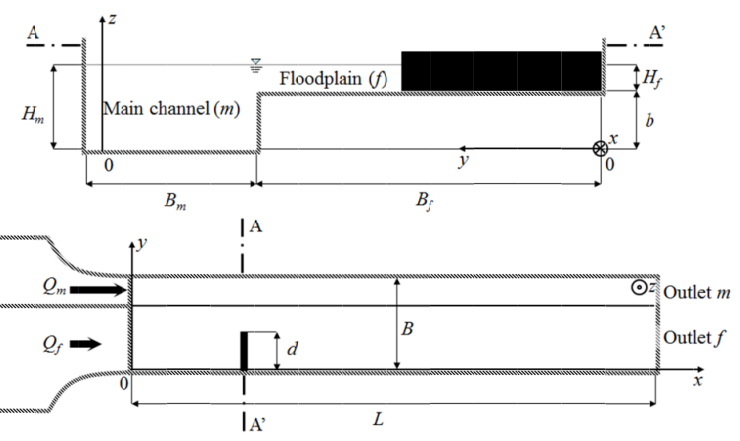

Figure 1 Definition sketch of the flume in the LMFA: cross-sectional and plan views (scheme is not to scale). 
623

624

625

626

627

628

629

630

631

632

633

634

635
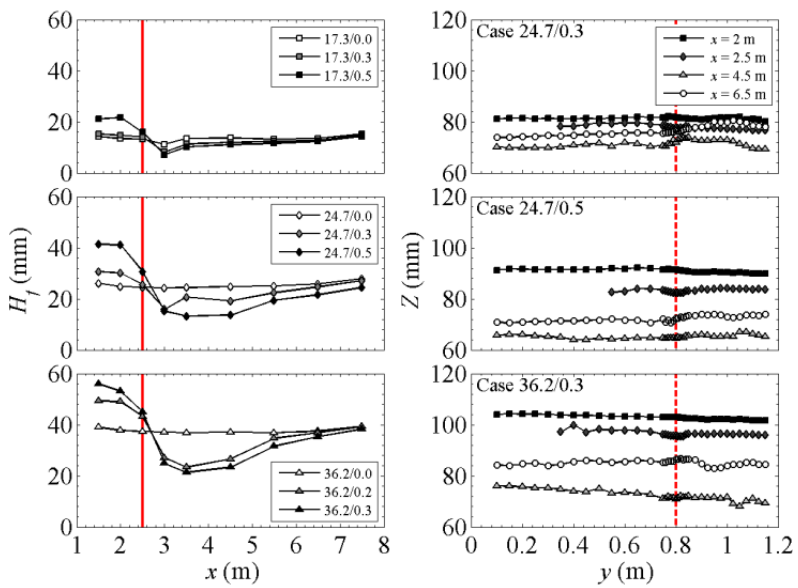

Figure 2 (Left plots) Longitudinal variations in the water depth on the floodplain, $H_{f}$, for the nine flow-cases. The black plain line corresponds to the $x$-wise position of the embankment. (Right plots). Lateral distribution of water level, Z. The dashed line corresponds to the junction of the sub-sections. Uncertainty: $\delta H= \pm 0.42 \mathrm{~mm}$ and $\delta Z= \pm 0.42 \mathrm{~mm}$.

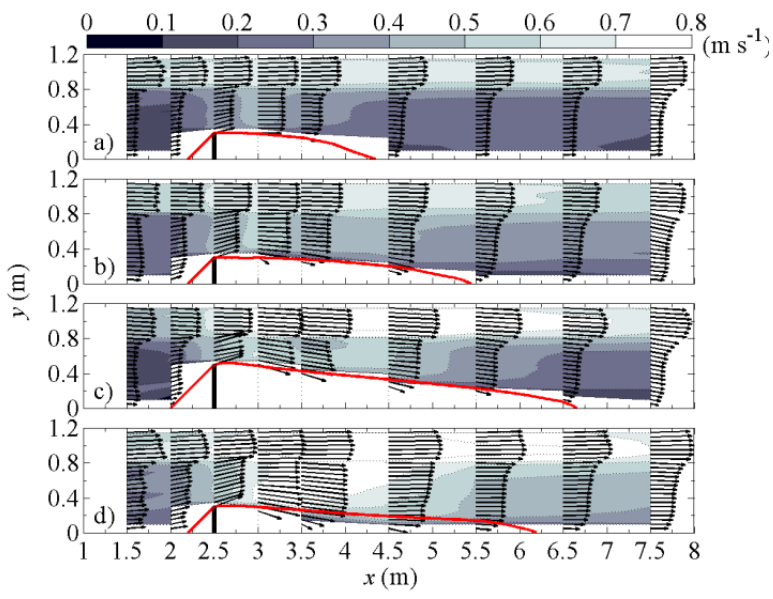

Figure 3 2D depth-averaged velocity fields for flow cases (a) 17.3/0.3, (b) $24.7 / 0.3$, (c) 24.7/0.5 and (d) 36.2/0.3 (presented in Table 1). The coloured surfaces represent the velocity intensity. The separation line between the recirculation zones and the main flow is identified by the bold black line. Uncertainty: $\delta U_{d} / U_{d}= \pm 1.5 \%$ and $\delta V_{d} / V_{d}= \pm 1.5 \%$.

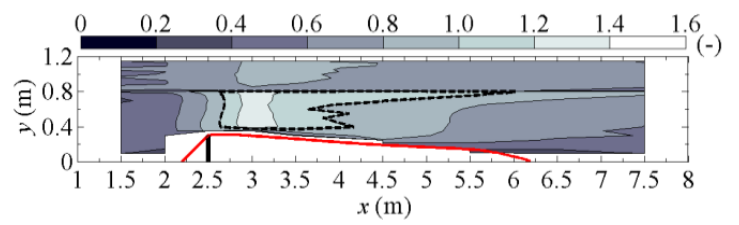

Figure 4 Froude number distribution for flow-case 24.7/0.3 (presented in Table 1). The black dashed line corresponds to $F=1$. 
636

637

638

639

640

641

642

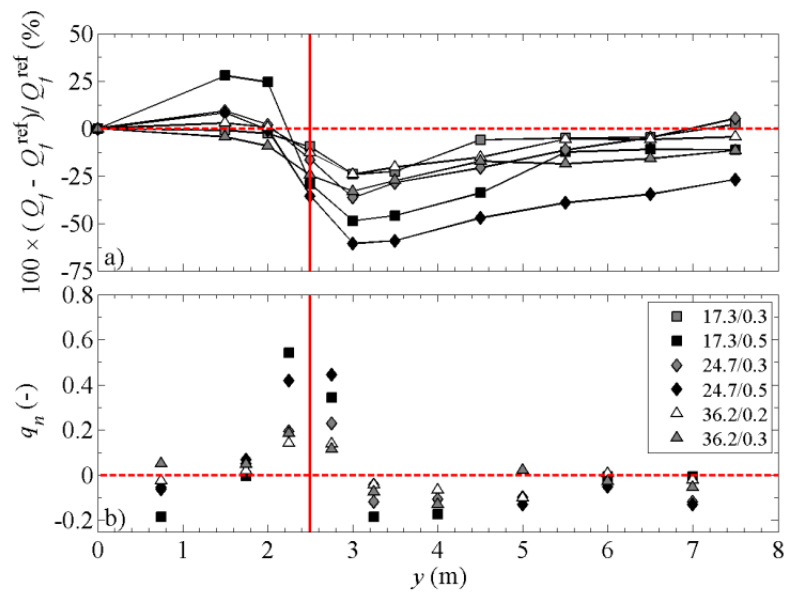

Figure 5 (a) Floodplain discharge, $Q_{f}$, compared to that for reference flows, $Q_{f}{ }^{\text {ref }}$. Uncertainty:

$\delta Q_{f} Q_{f}= \pm 5 \%$. (b) Normalised Intensity of lateral mass exchange per unit length, $q_{n}$, for the flow-cases with an embankment. Uncertainty: $\delta q_{n}= \pm 0.07$.

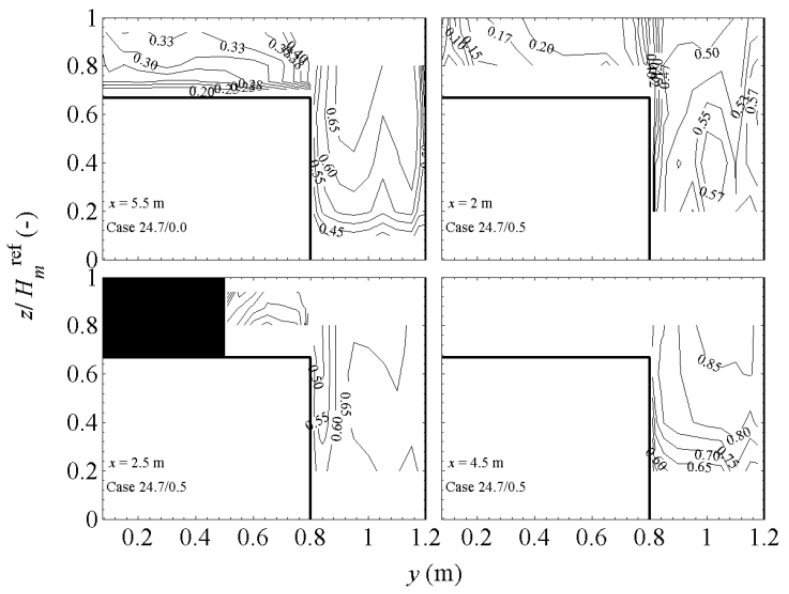

Figure 6 Cross-flow distribution of time-averaged longitudinal velocity, $\bar{u}$, for flow-cases 24.7/0.0 and 24.7/0.5. Uncertainty: $\delta \bar{u} / \bar{u}=1.5 \%$. 
643

644

645

646

647

648

649

650

651

652

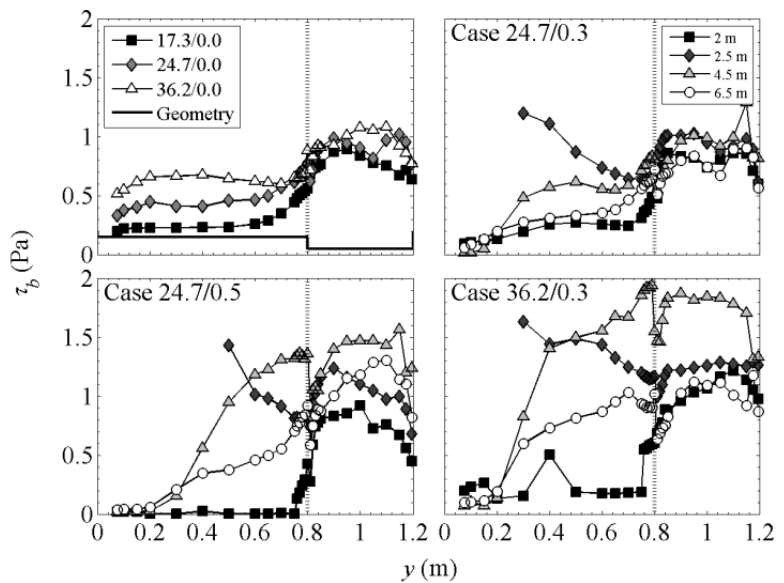

Figure 7 Lateral distribution of boundary shear stress, $\tau_{\mathrm{b}}$, measured under uniform flow conditions for flow-cases 17.3/0.0, 24.7/0.0 and 36.2/0.0 and with an embankment for flowcases $24.7 / 0.3,24.7 / 0.5$ and 36.2/0.3 (Table 1). Uncertainty: $\delta \tau_{\mathrm{b}} / \tau_{\mathrm{b}}= \pm 6 \%$.

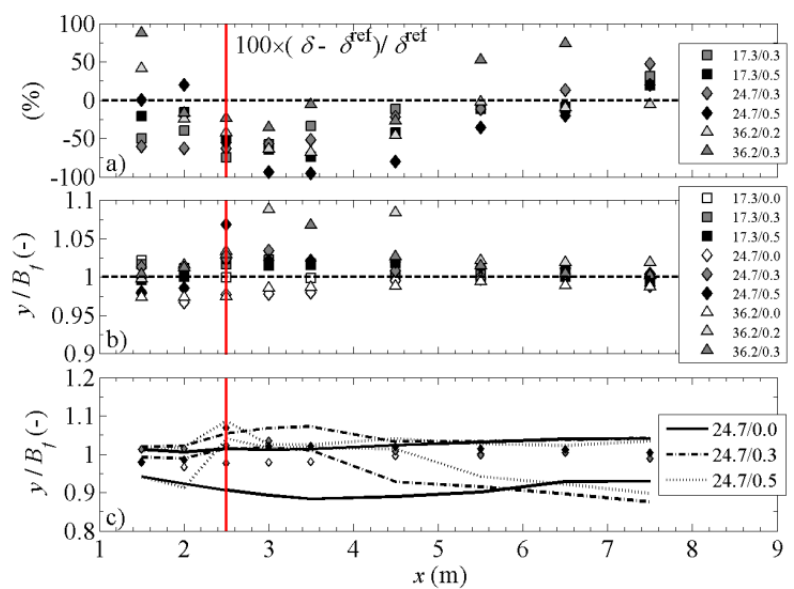

Figure 8 (a) Longitudinal variations in the width, $\delta(x)$, of the mixing layer developing between the sub-sections for the flow-cases with an embankment compared to the width, $\delta^{\text {ref }}(x)$, of the corresponding reference flows. (b) Position of the centre, $y_{c}(x)$, of the mixing layer. (c) $y_{c}(x)$ and outer boundaries, $y_{25}(x)$ and $y_{75}(x)$, of the mixing layer for the flow-cases 24.7/0.0, 24.7/0.3 and 24.7/0.5. Uncertainty: $\delta \delta(x)= \pm 2.5 \mathrm{~cm}, \delta y_{\alpha}(x)= \pm 1 \mathrm{~cm}$. 
653

654 655

656

657

658

659

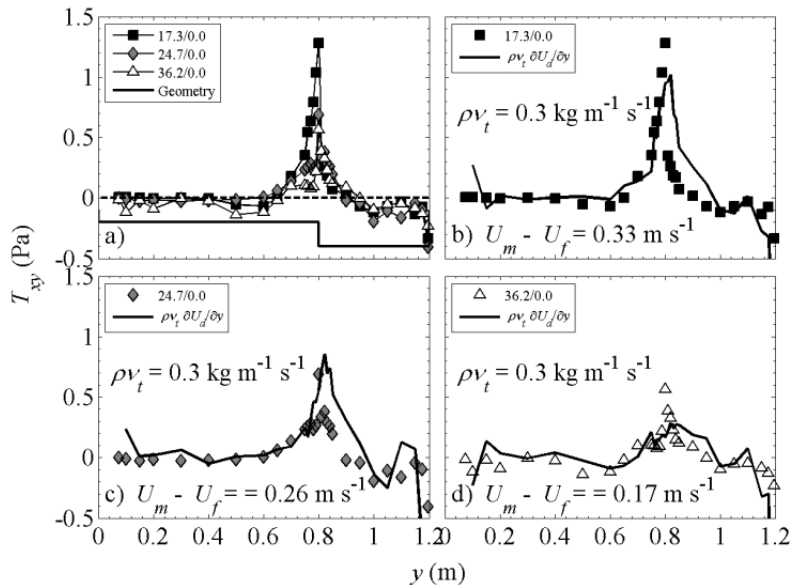

Figure 9 (a) Lateral distribution of depth-averaged Reynolds shear stress, $T_{x y}$, measured at $x=5.5 \mathrm{~m}$ for the reference flow-cases. (b-d) $T_{x y}$ compared to $\partial U_{d} / \partial y$.

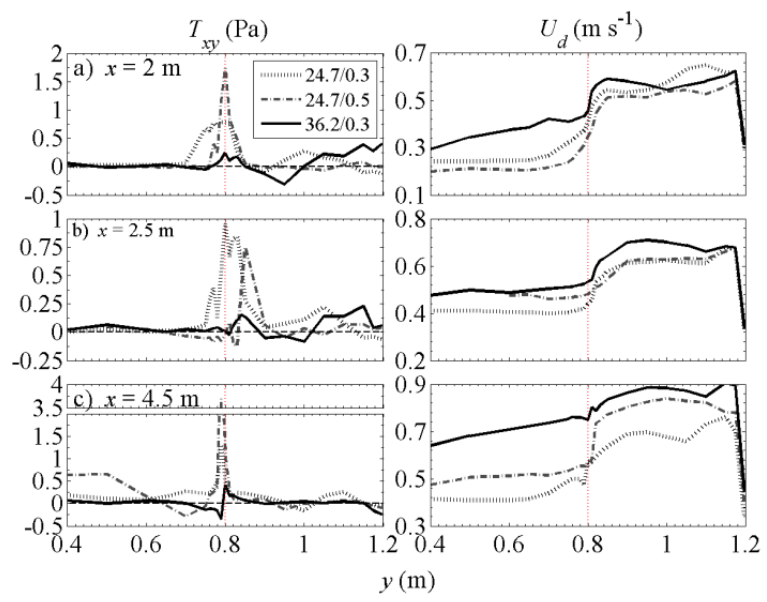

Figure 10 Lateral distributions of the depth-averaged Reynolds shear stress and depthaveraged longitudinal velocities for the flow-cases 24.7/0.3, 24.7/0.5 and 36.2/0.3 at three downstream distances. 